\section{Caring and curing: a philosophy of medicine and social work}

R S Downie and E Telfer London, Methuen, 1980, I74 pp $£ 3.95$

In recent years a number of disciplines outside the traditional range of biological sciences have staked modest claims in the medical curriculum. At a time of impressive developments in the natural sciences, claims of relevance to medicine by any new discipline need to appear very convincing indeed to achieve a sympathetic audience. This book is an attempt to demonstrate the value of philosophy not only to medical practitioners, but to the other 'caring professions' such as social work. The authors present their text as having two purposes - to introduce the reader to philosophy and to offer a philosophy of the caring professions.

The first chapter provides a discussion of the values and aims embodied in the professions of medicine and social work. This primarily revolves around a conceptual analysis of the meaning of 'health' and 'welfare'. The second chapter analyses some of the major moral principles which are claimed to govern the caring professions. They tease out the ethical issues that lie behind the apparent incompatability of active concern for the welfare of the client and a respect for his liberty.

They then move into the realms of political philosophy and draw out a wide range of implications behind the moral advocacy of laissez-faire, pluralist and socialist systems of providing care. Their fourth chapter can be taken as an introduction to the philosophy of science in which the epistemological basis of the natural and social sciences are examined in turn, and it is concluded that the social sciences are of only limited value in training the professions to deal with individuals. The last chapter argues that the caring professions are, by virtue of their responsibilities, particularly com- pelled to consider questions regarding the meaning of life and the meaningful life. A brief discussion concludes that a meaningful life in the sense of one enriched by experience is essential to an understanding of the meaning of life and essential also to providing compassionate help.

The authors have attempted to cover an ambitious range of such profound issues in a short text, and the result, in my opinion is uneven. The discussion on the politics of the caring professions works well and, not coincidentally, is the longest chapter. Proponents of all persuasions will find their approach stimulating. Essentially they attempt to separate out matters of principle and empirical questions behind the various stances on the Welfare State in what is becoming an increasingly urgent debate in contemporary Britain. On the other hand the discussion on the knowledge base of the professions seems to ignore many important developments associated with writers such as Feyerabend and Lakatos that make their radical separation of the epistemology of natural and social sciences outmoded. Above all their brief but spirited advocacy of literature to educate the professions seems an odd and unsubstantiated conclusion. The last chapter is surely too ambitious in offering a philosopher's approach to an analysis of the meaning of life in I9 pages.

The authors have valiantly and clearly shown how philosophers attempt to throw light on moral and political problems by conceptual clarification. The caring professions confront such dilemmas in specific problems of daily work. I am not convinced that this text has successfully bridged the chasm between conceptual analysis and practice and would like to see philosophers drawn into more specific issues to prove themselves.

RAY FITZPATRICK Department of Psychiatry Middlesex Hospital London
Values in Social Policy: nine contradictions

Jean Hardy, Routledge and Kegan Paul (Radical Social Policy Series), I98I, ix + I32 pp £4.95.

This book explores a series of contrasts which the author sees as central to discussion of the basis of the welfare state and of social work and social policy within it: for example, authority versus liberation, bureaucracy versus professionalism, the individual versus the community. One aim of the book is to help welfare workers to come to terms with conflict, to learn that their work is essentially a field of competing values in which there are no routine answers and personal moral choices have to be made. In many ways it succeeds admirably in its aim: it is clearly written, provocative andec reasonably jargon-free, and would? form a useful basis for general seminars in most fields of medical work, though it is written with social workers particularly in mind. For its size it has very full notes and bibliography.

I have two main criticisms of Values in Social Policy. The first is that it is written in terms of various contrasts which are not themselves explicitly explored, particularly that between capitalism and 'welfare society'. It is assumed throughout that we agree what capitalism is, what its bearings are on other questions raised (for example, on the nature of authority or of the family) and that modern Britain is basically capitalist. Only in the final chapter, 'The personal versus the political', do we get a slightly more extended discussion of capitalism, and this does not inspire confidence. For example, it equates 'rational and economic man' with 'the man who is both educated and with possessions'. This is not what the classical economists meant by the phrase. If Ms Hardy wishes to maintain that their system nevertheless requires such an interpretation, she would need to produce arguments to 
support her claim. Throughout the book there are far too many tendentious assertions in this vein without support or explanation, and a tendency to use quotation instead of argument.

My second criticism is that implications of concepts discussed are not really brought out. For example: a particular kind of individualism is criticised for being 'possessive'. But can any kind of individualism avoid being possessive in some measure, even if only of its own ideas and beliefs? (But in many ways I thought the chapter on the individual and the community the best in the book.) Again, if freedom is to be defined as "consciousness, moral awareness and the capacity to choose between actions and enter into beliefs' (p 95), can anything impair it, even the gross inequalities which are said to damage it ? These and others like them are of course large questions. I would not expect a full scale discussion of them but would have welcomed an acknowledgement that they do arise from any attempt to analyse the concepts discussed in this book.

RLIZABETH TELFER

Department of Moral Philosophy University of Glasgow

\section{Ethics in Nursing Practice and} Education

(American Nurses' Association) 1980 $65 \mathrm{pp} \$ 4.50$.

A nurse in the 1980 s may be confronted with a variety of complex issues, for which the custom and practice of the past is no longer a sufficient guide. Technical progress has created dilemmas which did not previously exist on the one hand, and on the other there is diversity of opinion where once there was a consensus. In addition, the nurse is also assuming an ever expanding role, especially when functioning as an independent practitioner away from the hierarchical hospital structure. The need for some kind of comprehensive text, like that of the British Medical Association's Handbook of Medical Ethics is indisputable. Any attempt to fill this gap must be welcomed.

This collection of seven papers from the American Nurses' Association sets out to consider two main areas, that of nursing practice and of nursing education. In the former the approach is mainly academic and tends to avoid coming to grips in a specific way with particular issues. There is some overlapping in the different papers, particularly in discussing a definition of ethics. It has also to be remembered that the training and context of practice of health care in America is at considerable variance with our own in Britain, not least in the matter of private funding. For any nurse seeking guidance, the Royal College of Nurses' Code of Professional Conduct is likely to prove as helpful.

The papers in the Education section are much more specific, and recognise the need for including a course of ethics in a nursing curriculum. The third paper, 'A Bioethical Program for Baccalaureate Nursing Students', gives an outline of the sort of approach that might be used in such a course. This is not only excellent as a model in this subject but is also valuable as an approach for teaching in any subject.

The British Medical Association's Handbook covers a whole range of issues thoroughly and sensitively; but only a page or so is devoted to nurses, and that in the context of their relationship to doctors. While the RCN has gone some way to meeting the need for a treatment of the special problems of nurses with such booklets as Guidelines on Confidentiality there is still a lack of a comprehensive British work on the subject.

P M KILSHAW Imperial College, University of London

\section{Muted Consent}

Jan Wojcik. Purdue University, Indiana, USA, 1978. I64 pp $\$ 3.35$.

This volume is one of a series on science, technology and human values from the Purdue University, West Lafayette, Indiana, USA. The author hopes that the book will be used as a 'primer in the language of medical ethics'. The book, in seven chapters, looks at various topics in medical ethics. Each chapter begins with three fictional case histories which illustrate the problems analysed in each chapter. The debate is clear and well illustrated with a number of references to contemporary commentators. The treatment of the material is mainly theoretical and philosophical. The quality of the case material is reduced by the fa that cases are hypothetical and the final outcome is not given. Ofte the complexity of cases illustrates the many principles that co-exist on considering case material. This book isolates the major stances taken debate on the issues covered.

It seems unclear if the book intended for doctors, medicgi

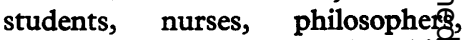
theologians or the general publig. The cases and the discussion suffer very much from bias towards the United States. Indeed the involve ment of the courts of law both cixil and criminal is very different in the two countries and the argumen thus suffer. Certainly some of the language is more suited to the philosopher than the medical student or young doctor trying to make sense of the dilemmas which face him.

The basic theme of the book 98 that all ethical problems have an involvement with altered consent in some form or another. Even if oxe cannot go the whole way with the interesting thesis it undoubted尊 emphasises a very important mest sage. Consent in its widest sense dहे essential for good ethical doctogng However, in some areas the probsem is not merely of consent but whocis give valid consent. Can the mother give consent for the death of he्g child or fetus? We accept that parents must be involved in $\mathrm{d} g$ cisions about their baby especially it is suffering from a serious cos genital malformation. In the area of death and dying can the patient give valid consent in a situation where is denied any real alternative? Ore chapter explores at considerable length the technical aspects of deat Other aspects receive less attention, in particular the development of the hospice movement in this country The chapter on resource allocation if clear and I enjoyed reading it very much. Again it has a US bi 정 emphasing the close involvement of the law courts.

I cannot advise any medical student to buy this book or ever suggest it as a primer, but, for tho\$ interested in medical ethics this is valuable source book. The references are extensive and the arguments of the various commentators are wef summarised. A book for the library rather than for the private collection

B T POTTER Royal Infirmary Edinburgh 